\title{
Leo Strauss, Carl Schmitt y la naturaleza de la política ${ }^{1}$
}

\author{
Leo Strauss, Carl Schmitt and the Nature of Politics \\ Leo Strauss, Carl Schmitt e a natureza da política
}

Daniel Mansuy*

Universidad de los Andes, Santiago de Chile, Santiago, Chile

\section{Resumen}

El presente artículo busca explicar la crítica formulada por Leo Strauss a la influyente obra de Carl Schmitt, El concepto de lo político, y el modo en que ella puede dar cuenta del desarrollo posterior del pensamiento straussiano. Para esto, se investiga el fundamento de la crítica schmittiana al liberalismo, poniendo especial énfasis en su relación con Thomas Hobbes; y se alude luego a su concepción de la moralidad. Se intenta determinar por qué, según Strauss, la crítica de Schmitt al pensamiento liberal es insuficiente, en cuanto no logra superar el horizonte del liberalismo.

Palabras clave: Leo Strauss. Carl Schmitt. Liberalismo. Thomas Hobbes. Filosofía política.

1 El autor agradece el apoyo de Fondecyt (proyecto n. 11121586).

*DM: Doctor en Ciencia Política, e-mail: dmansuy@uandes.cl 


\section{Abstract}

The purpose of this paper is to explain Leo Strauss' criticism of Carl Schmitt's seminal The Concept of the Political, and the way it is able to account for the further development of Straussian thought. In order to do so, the basis of the Schmittian criticism of liberalism is investigated, emphasizing its relation to the work of Thomas Hobbes; and his conception of morality is addressed afterwards. The author attempts to understand why, according to Strauss, Schmitt's critique of liberal thought is insufficient, insofar as it is unable to overcome the horizon of liberalism.

Keywords: Leo Strauss. Carl Schmitt. Liberalism. Thomas Hobbes. Political Philosophy.

\section{Resumo}

O presente artigo tem por objetivo explicar a crítica formulada por Leo Strauss à influente obra de Carl Schmitt, O Conceito do Político, a maneira em que ela pode demonstrar o desenvolvimento posterior do pensamento straussiano. Para tanto, pesquisa o fundamento da crítica schimittiana ao liberalismo, colocando especial ênfase na sua relação com Thomas Hobbes; e desenvolve logo a sua concepção de moralidade. Trata de determinar o porquê, segundo Strauss, a crítica de Schmitt ao pensamento liberal é insuficiente, já que não consegue superar o horizonte do liberalismo.

Palavras-chave: Leo Strauss. Carl Schmitt. Liberalism. Thomas Hobbes. Filosofia Política.

En 1965, Leo Strauss publicó en Estados Unidos uno de sus primeros trabajos, que había escrito en los años '20, sobre la crítica de Spinoza a la religión. Para la ocasión, decidió agregar un prefacio, que - según propia confesión - es algo así como una autobiografía intelectual $^{2}$. El texto es particularmente críptico y difícil de seguir, al punto que su amigo Gershom Scholem decía que sólo cinco o seis personas en

2 Carta de Leo Strauss a Gershom Scholem del 4 de mayo de 1962 (STRAUSS; SCHOLEM, 2010). 
el mundo podrían comprenderlo cabalmente ${ }^{3}$. En ese prefacio, Strauss explica cuáles fueron sus inquietudes intelectuales más tempranas y cómo, a partir de ellas, fue delineando su proyecto filosófico. En los últimos párrafos, Strauss realiza una observación que ilumina toda su trayectoria posterior: cuando escribí este libro, dice, no pensaba que un regreso a la filosofía premoderna fuese posible. Sin embargo, prosigue, me estaba empezando a preguntar si acaso la crisis de la razón moderna no era el fruto del racionalismo moderno, en tanto distinto del racionalismo premoderno - particularmente la filosofía griega y la filosofía judía medieval. Digamos que esta última interrogación contiene toda la filosofía de Strauss. El prefacio concluye puntualizando que la primera manifestación de este cambio de perspectiva (respecto de la posibilidad de considerar seriamente la racionalidad premoderna como una alternativa filosófica válida) fue su comentario al Concepto de lo político de Carl Schmitt (1932) (STRAUSS, 1997, p. 31; MEIER, 2008). En efecto, es sólo a partir de la discusión con Schmitt que Strauss empieza a ocuparse del problema de la escritura y de las relaciones entre política y filosofía, cuestiones que están en el centro de sus trabajos.

Podemos decir entonces que, según el propio reconocimiento de Strauss, la discusión con Schmitt fue decisiva en la configuración de su proyecto intelectual. Esto resulta interesante por varios motivos. Por un lado, la filosofía de Strauss es enigmática bajo muchos respectos, y sigue dando lugar a múltiples polémicas ${ }^{4}$. Por lo mismo, puede ser útil examinar su momento original, un poco como el mismo Strauss vuelve constantemente a examinar el origen de la modernidad para intentar comprenderla. Esto es relevante no sólo para los lectores de Strauss, sino también desde la perspectiva de Schmitt, quien consideraba que Strauss lo había comprendido correctamente ${ }^{5}$. De hecho, como ha mostrado convincentemente Heinrich Meier, el jurista alemán siguió por largos años dialogando con él de modo silencioso (MEIER, 2008; LURI, 2012, p. 120).

3 Carta de Gershom Scholem a Leo Strauss del 13 de diciembre de 1962 (STRAUSS; SCHOLEM, 2010).

4 Para un panorama general de los problemas en torno a Strauss, ver las siguientes recopilaciones de artículos: (SMITH, 2009; HILB, 2011).

5 En una carta del 10 de julio de 1932, Schmitt dice que la única crítica que le ha interesado es la de Strauss (LURI, 2012, p. 120). 
La afirmación straussiana (según la cual el diálogo con Schmitt es la primera prueba de su madurez intelectual) tiene, desde luego, muchos sentidos. Por de pronto, es importante aclarar que no consiste - ni de lejos - en la aceptación de una deuda. Aunque en la correspondencia que tienen antes de 1933, Strauss trata a Schmitt con suma deferencia, no hay nada en la obra de Strauss que nos permita afirmar que se sentía heredero del jurista alemán (ZUCKERT; ZUCKERT, 2006, p. 186). Lo que Strauss admite es que la confrontación con las tesis de Schmitt le permite vislumbrar la profundidad de algunos problemas que considera decisivos. Eso quiere decir que Schmitt le ayudó, voluntaria o involuntariamente, a comprender mejor el alcance de algunas preguntas.

Siguiendo el prefacio al que aludimos más arriba, podemos explicar la cuestión del modo siguiente: Schmitt le permite a Strauss percibir cuán necesaria es una crítica radical al liberalismo. Esto debe ser comprendido literalmente: la crítica radical es aquella que atiende a las raíces, que va al origen del fenómeno. En otras palabras, es indispensable preguntarse si la querella entre los antiguos y los modernos fue efectivamente zanjada, para saber si los fundamentos de la modernidad están bien asentados. La pregunta es de por sí un poco heterodoxa, porque - en alguna medida - la modernidad se funda precisamente en una suerte de superioridad autoevidente respecto de los paradigmas clásicos, que Strauss no cesará de interrogar a lo largo de su vida (STRAUSS, 1978, p. 95-96; LURI, 2012, p. 117). En las páginas que siguen, analizaremos la crítica de Strauss a Schmitt. En primer término, expondremos brevemente el núcleo argumental del Concepto de lo político. Luego, estudiaremos la relación problemática entre Schmitt y Hobbes a partir de las observaciones de Strauss; y nos preguntaremos por el papel de Maquiavelo en esta discusión. En seguida, trataremos de determinar la relación entre moral y política en el pensamiento schmittiano, pues allí residen muchas de las tensiones presentes en el texto. Finalmente, intentaremos explicar los problemas que enfrenta Schmitt a partir de una concepción inadecuada de la filosofía práctica. 


\section{Schmitt y lo político}

En este contexto, el diálogo con Schmitt marca un hito fundamental. En efecto, El concepto de lo político contiene una crítica enérgica a la versión liberal de la modernidad. Además, es uno de los pocos libros del siglo XX que pueden ser considerados como auténticos clásicos políticos. El argumento de Schmitt puede caracterizarse como una oposición frontal a la modernidad, en cuanto ésta busca pacificar el mundo para dejar que los hombres se ocupen tranquilamente de sus negocios privados. Digamos que Schmitt ataca sin piedad el proyecto de Benjamin Constant, quien describe la libertad moderna como el disfrute apacible de la independencia privada ${ }^{6}$. Este goce privado se hace posible a partir del auge del comercio y de la "cultura", que reemplazan en definitiva a la política. Esto permite neutralizar los conflictos, y dejar atrás las tensiones humanas que han dado forma a la historia.

A Schmitt parece preocuparle lo siguiente: en el mundo de Constant, no hay espacio para una política distinta de la mera gestión de intereses. Contra esta concepción liberal, Schmitt busca determinar el carácter específico del fenómeno político. El jurista alemán aclara que no busca definir exhaustivamente lo político, sino simplemente dar con el criterio que permita comprender su carácter específico y diferenciador respecto de otras realidades. Schmitt cree que lo político tiene que ver, en último término, con la oposición entre amigo y enemigo. Cualquier filosofía que proyecte o intente erradicar el conflicto de nuestras vidas busca, de modo más o menos consciente, amputar una dimensión fundamental de la existencia humana. Es interesante notar que Schmitt evade constantemente la pregunta de si algo así sería posible, porque le interesa simplemente sugerir que una vida humana sin conflicto ni tensión apenas merece ser vivida: sería una vida insoportablemente ligera, sin peso, para emplear los términos de Kundera ${ }^{7}$.

\footnotetext{
« Notre liberté, à nous, doit se composer de la jouissance paisible de l'indépendance privée » (CONSTANT, 1997, p. 602).

7 Hay motivos para suponer que esta argumentación de Schmitt contiene buenas dosis de retórica. En efecto, resulta Ilamativo que se niegue a entrar directamente al debate sobre si acaso el fin de la política es o no posible, pues hay en juego una cuestión central de filosofía de la historia que está en los fundamentos mismos de la modernidad, y que Schmitt no podía ignorar. Dice por ejemplo: "Si [...] desapareciese hasta la eventualidad de la distinción entre amigo y enemigo, en
} 
Por lo mismo, Schmitt afirma que no hay, propiamente hablando, una política liberal sui generis sino solamente una crítica liberal de la política (SCHMITT, 1998, p. 100). Si la especificidad de lo político reside en el conflicto, entonces el liberalismo se reduce a negar lo político, en cuanto tiende a negar o a eliminar el conflicto de nuestro horizonte ${ }^{8}$.

Strauss tiene más de un punto de acuerdo con Schmitt. Por de pronto, considera necesaria la crítica de cierta modernidad pues, según él, la racionalidad moderna - cuyos frutos son el positivismo y el historicismo - enfrenta una crisis sin precedentes ${ }^{9}$. De hecho, toda su obra puede ser leída desde ese ángulo, como un esfuerzo por comprender la crisis de la modernidad, como paso previo e indispensable a la posible superación de esa crisis. Por lo mismo, de más está decir que Strauss - como Schmitt- está lejos de compartir los ideales de la moderna filosofía de la historia. Basta acercarse, aunque fuera de lejos, a su diálogo con Kojève - el hegeliano más importante del siglo $X X$ - para percatarse de ello ${ }^{10}$. Sin embargo, para el autor de Derecho natural e historia, el intento de Schmitt no alcanza a responder a su propio desafío, como si quedara inevitablemente trunco. El marco general de la crítica es el siguiente. Schmitt afirma que todos los conceptos políticos tienen carácter polémico, en cuanto se vinculan a un antagonismo concreto (SCHMITT, 1998, p. 63). Esto parece dejar a Schmitt en una posición un tanto extraña: ¿cómo realizar una crítica política al liberalismo desde una posición que será tributaria de él, que admite estar existencialmente definida por él? Dicho de otro modo, ¿se puede criticar al liberalismo admitiendo por principio que la crítica está determinada por el liberalismo, en cuanto responde a un antagonismo determinado? ¿Es posible comprender la modernidad desde parámetros autónomos y no dependientes de la polémica? ¿Es posible elaborar

tal caso lo que habría sería una acepción del mundo, una cultura, una civilización, una economía, una moral, un derecho, un arte, un ocio, etc, químicamente libres de política, pero no habría ni política ni Estado. Yo no sé si semejante Estado de la humanidad se producirá alguna vez ni cuándo. De momento no lo hay" (SCHMITT, 1998, p. 84).

8 Una exposición detallada del argumento de Schmitt en Montserrat Herrero (1997, p. 235-296).

9 Ver los dos primeros capítulos de Natural Right and History (STRAUSS, 1953).

10 La discusión entre ambos está publicada como anexo a Strauss (2013). Este diálogo es fundamental para una adecuada comprensión del siglo XX.

Rev. Filos., Aurora, Curitiba, v. 30, n. 50, p. 397-423, maio/ago. 2018 
una crítica del liberalismo que supere el horizonte fijado por él? En el modo de responder estas preguntas reside el fondo del desacuerdo de Strauss con el jurista alemán.

\section{El problema de Hobbes}

Un buen ejemplo para percibir la naturaleza de estas dificultades reside en el uso de Hobbes por parte de Schmitt. Según el jurista alemán, Hobbes es el pensador político por excelencia ${ }^{11}$. ¿Por qué Hobbes sería el paradigma del filósofo que nunca pierde de vista el fenómeno específicamente político? Schmitt responde: porque es lúcido respecto de nuestra naturaleza conflictiva. La guerra hobbesiana de todo contra todos, dice Schmitt, no es "un engendro de una fantasía obcecada y cruel", sino los "presupuestos elementales de un sistema de ideas específicamente político" (SCHMITT, 1998, p. 95). Hobbes retrata al hombre sin hacerse ninguna falsa ilusión, y eso le permite, a ojos de Schmitt, conservar la especificidad de lo político.

Si seguimos a Strauss, Schmitt pierde de vista una dimensión esencial de la filosofía de Hobbes. En efecto, el Leviatán presenta el estado de naturaleza de manera polémica. Esto significa que la situación originaria, que es intrínsecamente violenta, está dibujada de tal modo que se haga necesario librarse de ella y salir de allí. El estado de naturaleza, que es precisamente donde está contenido el carácter político (conflictivo) del hombre, es por definición un estado transitorio. Si lo político es el conflicto, Hobbes lo niega antes de afirmarlo, porque su artificio busca neutralizarlo. Hobbes no afirma el estado de naturaleza como un lugar apropiado para el hombre, sino que resalta justamente su carácter insuficiente. Para Hobbes, en la situación originaria, los hombres "viven sin otra seguridad que la que su propia fuerza y su propia invención pueden proporcionarles" $\mathrm{y}$, por lo mismo, no hay "conocimiento de la faz de la tierra", ni "cómputo del tiempo, ni artes, ni letras, ni sociedad". Se trata, en definitiva, de una vida "solitaria,

11 Aunque reformula varias veces la expresión, tal parece ser la idea principal (MEIER, 2008, p. 58-59). 
pobre, tosca, embrutecida y breve" (solitary, poor, nasty, brutish and short) (Leviatán, XIII, p. 103). Hobbes se ve obligado a destacar los aspectos negativos del estado de naturaleza, porque así puede dar cuenta del contrato que funda la sociedad política: el estado de naturaleza hobbesiano está construido para ser negado en un momento posterior. Por eso, según Strauss, es eminentemente polémico: no se explica por sí mismo, sino que responde a una necesidad del sistema. La afirmación del conflicto en Hobbes, que tanto celebra Schmitt, parece tener entonces un carácter más bien relativo o, en cualquier caso, funcional a un objetivo pacificador.

Es cierto que Hobbes reconoce la persistencia del estado de naturaleza entre naciones, un aspecto que es de especial interés para Schmitt. Pero Strauss anota aquí otra tensión. Lo propio del conflicto propiamente político, según Schmitt, es que la comunidad puede exigir de sus miembros que sacrifiquen su vida ${ }^{12}$. El carácter grave de lo político viene dado justamente por esta posibilidad: el conflicto político se da en cuanto existe la posibilidad de eliminación física, que la comunidad puede exigir del individuo. Con todo, esto no encaja con facilidad en el sistema de Hobbes. Para el filósofo inglés, la fundación del Estado encuentra su razón última en la protección de los derechos individuales, y el primero de ellos es la propia conservación ${ }^{13}$. En esa lógica, la colectividad no puede exigir el sacrificio de la vida, porque estaría negando su motivo fundamental de existencia: la sociedad política existe para librarnos de la muerte violenta y, por lo mismo, no puede exigirnos morir por ella. Una afirmación así es un perfecto contrasentido, y de hecho Hobbes no puede explicar la pena de muerte ${ }^{14}$ ni el deber de

12 "Una unidad política tiene que poder pedir en caso extremo el sacrificio de la propia vida. Para el individualismo del pensamiento liberal semejante pretensión no es asequible ni susceptible de fundamentación" (SCHMITT, 1998, p. 100).

13 "La causa final, fin o designio de los hombres (que naturalmente aman la libertad y el dominio sobre los demás) al introducir esta restricción sobre sí mismos (en la que los vemos vivir formando Estados) es el cuidado de su propia conservación y, por añadidura, el logro de una vida más armónica" (Leviatán, XVII, p. 137). El afán "armónico" está presente en Hobbes, pero es completamente ajeno a las concepciones schmittianas.

14 Hobbes afirma, por un lado, que los súbditos no tienen derecho a quejarse por las acciones del soberano, ya que éste tiene pleno derecho para juzgar de los medios necesarios para la conservación de la paz: "cualquier cosa que el soberano haga no puede constituir injuria para ninguno de sus súbditos, ni debe ser acusado de injusticia por ninguno de ellos. En efecto, quien hace una cosa por autorización de otro, no comete injuria alguna contra aquel por cuya autorización actúa". Por lo mismo,

Rev. Filos., Aurora, Curitiba, v. 30, n. 50, p. 397-423, maio/ago. 2018 


\section{defender el Estado ${ }^{15}$ (y de allí las dificultades consiguientes de Schmitt para explicar el derecho de resistencia en Hobbes ${ }^{16}$ ). No sorprende en- tonces que Strauss llegue a afirmar que Hobbes es - en términos es- trictamente schmittianos - el pensador antipolítico por excelencia. La dependencia de Schmitt respecto de Hobbes prueba, como ha sugerido Pierre Manent, la exactitud de la hipótesis inicial de Schmitt: el libera- lismo reina sin obstáculos, pues hasta sus críticos más radicales están sometidos a él (MANENT, 1990, p. 10) ${ }^{17}$.}

"quien se queja de injuria por parte del soberano, protesta contra algo de que él mismo es autor". El soberano es el único juez de los medios para lograr la paz (Leviatán, XVIII, p. 145). En toda lógica entonces, el soberano tiene "poder de vida y muerte" sobre sus súbditos, porque "nada puede hacer un representante soberano a un súbdito que pueda propiamente ser llamado injusticia 0 injuria". Es más, "un súbdito puede ser condenado a muerte por mandato del poder soberano" sin haber hecho "nada malo", pues la pregunta no versa sobre el crimen cometido, sino sobre el daño que "podría hacer" (XXI, p. 174). Sin embargo, hay aquí una tensión, pues en el capítulo XIV Hobbes había señalado que hay algunos derechos que nadie abandona. Un hombre, por ejemplo, "no puede renunciar al derecho de resistir a quien le asalta por la fuerza para arrancarle la vida" (XIV, p. 109), porque el único motivo por el cual el hombre cede derechos es para conservarse mejor. Por lo mismo, cada súbdito "tiene libertad en todas aquellas cosas cuyo derecho no puede ser transferido mediante pacto", y el hombre tiene entonces "libertad para desobedecer" si alguien quiere atacarlo (XXI, p. 177). En rigor, hay un regreso al estado de naturaleza en esta relación. El soberano tiene pleno derecho a condenar a muerte, y el súbdito tiene el mismo pleno derecho a resistirse: tal es la paradoja contenida en el sistema de Hobbes.

15 "Un hombre a quien como soldado se le ordena luchar contra el enemigo, aunque su soberano tenga derecho bastante para castigar su negativa con la muerte, puede no obstante, en ciertos casos, rehusar sin injusticia" (XXI, p. 178). El ejemplo que da Hobbes es bien ilustrativo: ese hombre puede pagarle a un soldado sustituto. Aquello que Schmitt considera que es lo específicamente político, Hobbes lo ve como una exigencia intercambiable, transable en el mercado de "servicios". Sigue Hobbes: "Cuando luchan los ejércitos, en uno de los dos bandos o en ambos se dan casos de abandono; sin embargo, cuando no obedecen a traición, sino a miedo, no se estiman injustos, sino deshonrosos. Por la misma razón, evitar la batalla no es injusticia, sino cobardía" (XXI, p. 178). El soberano no puede exigirle a nadie que muera por él, porque aquello es contrario al pacto: el derecho a matar al súbdito no implica un derecho a exigir que el súbdito entregue su vida por una causa. De hecho, "la obligación de los súbditos con respecto al soberano se comprende que no ha de durar ni más ni menos que lo que dure el poder mediante el cual tiene capacidad para protegerlos": "el derecho que los hombres tienen, por naturaleza, a protegerse a sí mismos, cuando ninguno puede protegerlos, no puede ser renunciado por ningún pacto" (XXI, p. 180). Una exigencia como la sugerida por Schmitt es necesariamente incompatible con una fundación individualista de la sociedad. De allí lo equívoca de su alusión a Hobbes. Como dice Éric Desmons, "la fragilización de la defensa nacional está [.. . ] inscrita en los fundamentos de la filosofía política de Hobbes" (DESMONS, 2001, p. 55): en el mundo de Hobbes, no hay espacio para un sacrificio en nombre de algo que exceda la seguridad individual.

16 En su libro sobre Hobbes de 1938, Schmitt insiste en que no puede pensarse, desde Hobbes, en un derecho de resistencia del individuo respecto del soberano (SCHMITT, 1992, p. 46-67). Sin embargo, como lo único irreductible en Hobbes es el individuo, éste siempre podrá resistir (ZARKA, 2009, p. 68).

17 Este texto es el prefacio de la edición francesa del Dialogo entre ausentes de Heinrich Meier (1990). Según Manent, es probable que esa mezcla entre hostilidad radical y dependencia profunda respecto del liberalismo sea la fuente intelectual de la elección política que hiciera Schmitt en 1933.

Rev. Filos., Aurora, Curitiba, v. 30, n. 50, p. 397-423, maio/ago. 2018 
Para Strauss, el equívoco respecto de Hobbes constituye un problema de primera importancia. Schmitt busca fundar una crítica de la modernidad liberal desde el autor del Leviatán, aparentemente sin percatarse de se trata precisamente del iniciador de esa tradición. De hecho, todos los fenómenos que Schmitt critica con tanta agudeza encuentran en él sus primeras manifestaciones (MEIER, 2008, p. 56). En su propio libro sobre Hobbes, que publicaría pocos años después, Strauss dedica un capítulo a intentar mostrar que la moral de Hobbes es, en el fondo, una moral burguesa y liberal, que busca la satisfacción de los intereses privados en cuanto el objetivo es pacificar los instintos violentos del hombre. Para Strauss, Hobbes reemplaza el honor, propio de la virtud aristocrática, por el miedo a la muerte violenta como fundamento de la moralidad (2006, p. 163). Si la naturaleza es peligrosa, en la medida en que contiene la posibilidad de muerte violenta, entonces el hombre debe alejarse de esos riesgos por medio de su industria y trabajo: "el comercio y la industria", dice Strauss, "han de ser más valorados que la agricultura y la pesca" (2006, p. 174), en cuanto lo alejan más del estado primario de necesidad. En ese sentido, la filosofía política de Hobbes es el "testimonio más importante" de la lucha librada contra la aristocracia "en nombre de la virtud burguesa" (STRAUSS, 2006, p. 175): en rigor, "su moralidad es la moralidad del mundo burgués" (2006, p. 169). Michael Oakeshott lo explica del modo siguiente: la moral hobbesiana de la seguridad no tiene ninguna necesidad de nobleza, ni de generosidad ni de magnanimidad, porque ninguna de esas cualidades provee de seguridad (OAKESHOTT, 2011, p. 158) ${ }^{18}$. Las virtudes aristocráticas y heroicas, fundadas en la vanidad antes que en el miedo, son naturalmente fuente de conflicto; mientras que las virtudes burguesas, fundadas en el miedo antes que en la vanidad, son más coherentes con la búsqueda de paz.

Este esfuerzo de Hobbes por pacificar el mundo llega bastante lejos, y excede los límites de la moralidad: según el autor inglés, una

18 Según Oakeshott, las páginas de Strauss que explican este cambio de paradigma moral se cuentan entre "las más penetrantes y brillantes de su libro" (OAKESHOTT, 2011, p. 173). Albert 0. Hirschman tiene una visión distinta: según él, Hobbes presenta una crítica muy severa hacia las virtudes heroicas y aristocráticas, pero no hay una proposición de moral burguesa para reemplazar la vieja moralidad (HIRSCHMAN, 1997, p. 15-16).

Rev. Filos., Aurora, Curitiba, v. 30, n. 50, p. 397-423, maio/ago. 2018 
reflexión industriosa es capaz de descubrir los principios racionales que podrían fundar una constitución que dure para siempre ${ }^{19}$. ¿Qué implica eso sino que es posible pacificar de modo definitivo el mundo humano por medio de una "reflexión industriosa"? Hobbes confía en que la racionalidad humana pueda acabar con el conflicto, esto es, confía en que aplicando un determinado método seremos capaces de encontrar un orden político donde el conflicto ya no tenga ningún lugar. Es cierto que Hobbes hace la salvedad de la política internacional - que es justamente la dimensión en la que Schmitt pone el acento-, pero puede pensarse que se trata de un problema de grado: ¿por qué no esperar que la reflexión industriosa también sea capaz de encontrar los principios de un orden internacional que dure para siempre? ¿No es acaso ése el propósito de Kant que, en este sentido, está en perfecta continuidad respecto de Hobbes ${ }^{20}$ ? Hay en el pensador inglés un germen remoto de lo que será la filosofía de la historia en los siglos XVIII y XIX: una confianza en las bondades del desarrollo de la razón, que lo ponen más cerca de Hegel que de Schmitt.

Puede decirse que Hobbes participa de un movimiento que, a partir de una consideración pesimista de la naturaleza humana, busca neutralizar nuestros instintos agresivos, satisfaciendo nuestras pasiones de modo pacífico y apolítico. En cualquier caso, el pensador inglés está mucho más dentro que fuera de esa tradición. De hecho, quizás sea el primer autor en dar una apariencia política a tendencias que son más bien despolitizantes: Hobbes hace filosofía política rehuyendo el conflicto y la deliberación; Hobbes hace filosofía política desde la convicción de que la política es fuente de conflictos y que, en consecuencia, debe ser minimizada. Así, por ejemplo, desarrolla una larga argumentación para justificar su preferencia por la monarquía por sobre

19 "There may principles of reason be found out, by industrious meditation, to make their constitution, excepting by external violence, everlasting" (Leviatán, XXX). La traducción al español de este pasaje en la edición del FCE es incorrecta, pues dice: "Así, mucho tiempo después de que los hombres comenzaran a construir Estados, imperfectos y susceptibles de caer en el desorden, pudieron hallarse, por medio de una meditación laboriosa, principios de razón, que hicieran su constitución duradera (excepto contra la violencia externa)" (XXX, p. 277). Sin embargo, el everlasting de Hobbes es mucho más fuerte que "duradera"; $y$ hay además un error en los tiempos verbales (la versión española sugiere que esos principios ya fueron encontrados, mientras que el original de Hobbes sugiere más bien que se trata de una posibilidad abierta).

20 Ver Immanuel Kant (1998). 
los gobiernos populares. El argumento subyacente es que la actividad política constituye una amenaza para el mayor bien humano: la paz. Dado que la monarquía es el régimen que menos necesita de política, es preferible a las otras formas de gobierno: Hobbes no tiene ningún aprecio por lo que ocurre en las asambleas deliberantes, ni tiene ninguna confianza en el arte político de la persuasión ${ }^{21}$. En Hobbes, el ciudadano que se ocupa de asuntos públicos queda necesariamente desvalorizado, y es visto como un peligro. Para el filósofo inglés, incluso el ocio representa un riesgo importante: los hombres que tienen mucho tiempo, señala, lo emplean en discurrir sobre la cuestión pública, y a leer a historiadores, oradores, poetas y políticos. Todo esto los llena de "grandes pensamientos", y se creen entonces capaces de llevar los asuntos públicos. Sin embargo, si no logran lo que creen merecer, se frustran, y desean el fracaso de quienes gobiernan (De Cive, XII, 10). Este tipo de argumentaciones, frecuentes en sus textos, empujan hacia eso que Strauss llamaba la nueva moralidad de Hobbes. En efecto, tanto el aristócrata ocioso como el político lector de historias antiguas constituyen una fuente de conflictos políticos; mientras que el burgués ocupado por sus negocios privados es fuente de paz y prosperidad: Hobbes sugiere que una vida volcada a la producción es la mejor manera de lograr la paz civil. En ese sentido, en la configuración del sistema de Hobbes está inscrito el fin de la política.

21 Por un lado, considera que las pasiones que mueven las asambleas son peligrosas pues, a diferencia de las pasiones individuales, las pasiones colectivas se asemejan al calor de la llama: son como "antorchas diversas que mutuamente se inflaman", y que incendian al Estado (Leviatán, XXV, p. 215-216). Esto ocurre porque los oradores de las asambleas no dicen Io bueno ni lo justo, sino que sólo persiguen alimentar su propia vanidad (XXV, p. 215-216; ver también Elementos de Derecho Natural y Político, II, 5, 4). Lo propio de la elocuencia y la persuasión, dice Hobbes, es hacer pasar por justo aquello que sirve la intención del orador. El orador hace esto razonando sobre principios falsos y opiniones vulgares "que casi siempre son falsos": el orador busca "acomodar su discurso a las pasiones de aquellos que quiere tocar (De Cive, X, 11. Hay aquí una crítica severa a Aristóteles, cuya filosofía política toma en serio las opiniones de los ciudadanos, porque son el elemento propio de la realidad política). Por último, la asamblea produce naturalmente facciones que pueden degenerar en guerra civil (De Cive, $X, 12)$. 


\section{Entre Maquiavelo y Hobbes}

Con todo, es interesante notar que, desde la perspectiva de Schmitt, podría haber sido más útil rescatar a Maquiavelo. Éste afirma, por ejemplo, el carácter decisivo del conflicto entre diversos grupos: el orden político no puede ser pensado al margen del horizonte del conflicto externo. Para demostrarlo, emprende en los Discursos sobre la primera Década de Tito Livio una larga comparación entre las repúblicas aristocráticas (como Esparta y Venecia) y las repúblicas democráticas (como Roma). La ventaja de Roma respecto de los modelos aristocráticos es su capacidad para acoger el movimiento del mundo, cuya naturaleza es eminentemente conflictiva: el régimen romano asume plenamente el carácter inestable del mundo, la existencia inevitable de enemigos (Discursos, I, 4-6). Por otro lado, el autor del Príncipe reivindica, como no lo hará ninguno de sus sucesores, las virtudes bélicas en cuanto ellas son capaces de asumir la conflictividad política. Es cierto que Maquiavelo puede ser considerado como el iniciador de la modernidad política en cuanto elabora una antropología donde las pasiones tienen una primacía indiscutible (El Príncipe, III y XV), pero no cree que esas pasiones puedan ser neutralizadas. Por lo mismo, hay en Maquiavelo una constante exaltación de la gloria, de la guerra y, en definitiva, del conflicto: no hay manera de huir de todo ello. Es más, el modelo republicano de Maquiavelo - como lo sugiere Thierry Ménissier - logra la paz interna a partir de un desplazamiento de la violencia hacia el exterior: la unidad de la polis depende de la guerra exterior, depende del enemigo (MÉNISSIER, 2010, p. 116-117). Y, por cierto, no hay norma alguna capaz de ordenar la realidad, ni de imponer límites previos a la acción humana: la filosofía política de Maquiavelo está abierta como ninguna otra a la excepción. Ya que el hombre es un animal agresivo, la política debe intentar servirse de esa agresividad más que intentar dominarla: tal parece ser la máxima del Florentino. En virtud de lo anterior, es difícil hallar en Maquiavelo rastros de filosofía de la historia: el conflicto constituye una realidad insuperable. Ninguna teoría política podrá controlar ni pacificar las pasiones: es inútil querer transformar 
la naturaleza humana. Por lo mismo, no hay en Maquiavelo ninguna especie de optimismo histórico (MÉNISSIER, 2010, p. 141) 22.

¿Por qué, entonces, Schmitt prefiere a Hobbes, cuando el pensamiento de Maquiavelo podría haberle sido tanto o más útil para sus objetivos? Es cierto que su posición respecto del Florentino varió con el tiempo, lo que incluso se refleja en las sucesivas ediciones del Concepto de lo político ${ }^{23}$, pero como bien afirma Carlo Galli, el pensamiento de Maquiavelo parece haber quedado siempre al exterior de la filosofía schmittiana. El autor del Príncipe no comprendió, a ojos de Schmitt, el carácter simbólico del Estado, que le permite encarnar la protección ante el peligro de muerte, cosa que sí ocurre en Hobbes. Dicho de otro modo, en Maquiavelo no hay majestad de la representación, sino que el poder queda desnudo y descubierto, y no ve por tanto la dimensión misteriosa del poder político (GALLI, 2010, p. 116-117). La diferencia, nos parece, radica en la noción misma de Estado: en cuanto Hobbes es el auténtico creador del Estado moderno, se trata de un pensador específicamente político. Pero la pregunta es precisamente en qué medida el Estado moderno es un instrumento propiamente político: si el Estado es un esfuerzo por pacificar nuestra tendencia al conflicto, entonces su naturaleza es más ambigua de lo que pretende Schmitt. Carlo Galli vislumbra bien el problema, cuando afirma que mientras Maquiavelo no le teme al conflicto, y lo acepta "en cuanto constitutivo de la política como hecho humano colectivo", Schmitt sí le teme al conflicto (GALLI, 2010, p. 123). De hecho, el jurista alemán sabe bien que la tarea de un "Estado normal" consiste básicamente "en producir dentro del Estado y su territorio una pacificación completa, esto es, en procurar paz, seguridad y orden" (SCHMITT, 1998, p. 76). Naturalmente, esa pacificación interna se realiza en vistas a conseguir la unidad necesaria para enfrentar la posibilidad de conflicto externo. Sin embargo, como vimos, puede pensarse que la pacificación internacional no es sino una etapa más del mismo proceso, en virtud de los mismos fundamentos antropológicos.

22 Sobre la relación entre Schmitt, Maquiavelo y Strauss, ver Howse (1997, p. 87-91).

23 En la edición de 1932, Schmitt incluye a Maquiavelo en el listado de pensadores "específicamente políticos", que presuponen cierta "maldad" en el hombre (SCHMITT, 1998, p. 91-92). En La dictadura, Schmitt ve a Maquiavelo como un pensador ocupado por "problemas puramente técnicos y de ciencia militar" lo que, en boca de Schmitt, no vale por elogio (SCHMITT, 1999, p. 39). 
En todo caso, cabe notar que en su libro sobre el Leviatán - publicado en 1938 - , Schmitt corrige en parte sus juicios sobre el filósofo británico. En efecto, allí admite que la modernidad liberal, de algún modo, encuentra su origen en el pensamiento de Hobbes. Por un lado, el contrato hobbesiano está concebido de modo perfectamente individualista, pues disuelve todos los vínculos y comunidades (SCHMITT, 1992, p. 33). Al mismo tiempo, Schmitt reconoce que el Estado puede transformarse en un instrumento técnico neutro susceptible de servir a los más diversos fines (1992, p. 42); y que fue Hobbes el primero en haber conceptualizado la idea del Estado como un artificio, como máquina que encuentra su verdad en su eficacia y su función (SCHMITT, 1992, p. 45-46) ${ }^{24}$. Para explicar este proceso, Schmitt le atribuye mucha importancia a la doctrina de los milagros. Hobbes sería, según el jurista germano, un agnóstico respecto de los milagros: ni afirma ni niega. Con todo, reconoce la potestad al soberano para definir qué debe ser creído como milagro y qué no. Sin embargo, y aquí reside según Schmitt la grieta del poder soberano que debía unir religión y política, Hobbes introduce una "restricción individualista", al distinguir entre creencia interna y confesión externa: el Estado no puede obligar a creer en fuero interno, sólo puede obligar a confesar de modo externo ${ }^{25}$. Para Schmitt, el Estado liberal de derecho se deduce lógicamente a partir de esta distinción que supone una distinción radical entre lo público y lo privado $^{26}$ (SCHMITT, 1992, p. 55-56). Podemos suponer que la crítica de Strauss y su libro sobre Hobbes juegan un papel fundamental en la revisión que hace Schmitt respecto de Hobbes: ya no puede considerarlo

24 Puede decirse que en el Hobbes de Schmitt hay una tensión insoluble entre la consideración del Estado como mecanismo y la consideración del Estado como mito (lo que relativiza la crítica de Schmitt a Maquiavelo: en Hobbes el poder también aparece desnudo, y las dificultades del mito asociado a la figura del Leviatán son enormes). Sobre esto, ver Muller (2011); el capítulo tercero de Meier (2013); y la introducción de Étienne Balibar a la edición francesa de The Leviathan in the State Theory of Thomas Hobbes (BALIBAR, 2002).

25 Sobre este problema en Hobbes, ver Hüning (2007).

26 Según Schmitt, pocos años después de publicado el Leviatán, "la mirada del primer judío liberal se dirigió sobre esta grieta apenas perceptible", y"reconoció de inmediato la gran fractura" por donde pasaría el liberalismo moderno (1992, p. 57). Se trata, desde luego, de Spinoza y su Tratado teológico-político. Páginas más tarde, Schmitt también criticará la concepción que Hobbes tenía de la monarquía: al desvincularla de sus fundamentos tradicionales, la convirtió en "una simple forma fenoménica de un sistema de legalidad estatal" (SCHMITT, 1992, p. 82-83). Sobre todo esto, ver Gregorio Saravia (2011, p. 154-165). 
sin más como estando fuera de la tradición liberal. Su posición sobre Hobbes se vuelve mucho más ambigua.

Sin embargo, hay una idea que Schmitt mantiene en su trabajo sobre el Leviatán, y que devela bien el profundo desacuerdo que tiene con Strauss. Para este último, Hobbes es un ateo materialista, que disimula sus convicciones por motivos tácticos. Según el autor de La ciudad y el hombre, es imposible comprender adecuadamente a Hobbes sin considerar este aspecto ${ }^{27}$. Por su parte, Schmitt considera que Hobbes era un creyente sincero, incluso si su filosofía no es la propia de un creyente (SCHMITT, 1992, p. 83). De hecho, en una larga nota agregada en 1963 al Concepto de lo político, Schmitt parece discutir directamente con Strauss, y asevera que el sistema de Hobbes está abierto a la trascendencia. La fe de Hobbes, según Schmitt, no es una simple declaración táctica de protección ni una mentira piadosa que le permite salvar la censura. Más bien, dice, es "la piedra angular" de su construcción política" (SCHMITT, 1998, p. 179) ${ }^{28}$. Naturalmente, un conflicto abierto a la trascendencia no es lo mismo que un conflicto cerrado a ella ${ }^{29}$. Si el Leviatán de Hobbes es un mito que encuentra su sentido último en la trascendencia y en los misterios de la fe, su función no es puramente mecánica, sino que aspira a dar cuenta de una tendencia humana que no se agota en la materialidad ni en los apetitos sensibles. Más allá de sus defectos intrínsecos y de sus fundamentos individualistas, Schmitt cree que hay algo más profundo en el sistema de Hobbes: es un símbolo que unifica a un grupo de hombres. Esto explica buena parte de sus diferencias con Strauss.

27 Ver Strauss (2006, p. 109-115) y (2010, p. 177-183), donde se afirma que "la incredulidad de Hobbes es la premisa necesaria de su enseñanza sobre el estado de naturaleza" (2010, p. 183).

28 Es importante notar, en todo caso, que en 1938 Schmitt aceptaba la existencia de escritura esotérica en Hobbes: éste tenía, "como todos los grandes pensadores de su época, el sentido de la disimulación esotérica; y dijo de sí mismo que a veces hacía aperturas, pero que no develaba sino a medias sus verdaderos pensamientos" (SCHMITT, 1992, p. 26).

29 A partir de este tipo de consideraciones, Heinrich Meier ha desarrollado una larga argumentación para intentar demostrar que la diferencia entre Schmitt y Strauss es, en último término, teológica. Según Meier, Strauss elabora una filosofía política a partir de la figura de Sócrates, y Schmitt una teología política a partir de su fe católica. Esta tesis es discutible, entre otros motivos porque Meier nunca logra explicar claramente en qué podría consistir algo así como una teología política católica (MANENT, 2014, p. 431-433). 
Con todo, la ambigüedad y las oscilaciones de Schmitt a propósito Hobbes son iluminadoras de las variaciones de su propio pensamiento: su crítica al liberalismo queda comprometida por sus equívocos respecto de Hobbes. En efecto, ¿cómo comprender el liberalismo sin comprender adecuadamente el Leviatán? El problema puede explicarse así: Schmitt queda atado a la noción de Estado, y quiere elaborar una crítica radical al liberalismo a partir de la noción de Estado. Sin embargo, puede pensarse que el Estado moderno es, de algún modo, una construcción liberal, o al menos plenamente coherente con el liberalismo. Si esto es plausible, entonces cualquier crítica al liberalismo implica tomar alguna distancia con el concepto de Estado, cosa que Schmitt no está dispuesto a hacer ${ }^{30}$.

\section{Moral y política}

Pero ¿qué significa, en definitiva, la afirmación de lo político? Para Schmitt, parece tratarse de la afirmación del carácter peligroso de nuestra condición: en el hombre, el conflicto está siempre latente ${ }^{31}$. Hobbes lo explica a partir de una antropología de la maldad humana. Strauss anota que es muy importante, en ese contexto, comprender que la maldad a la que alude Hobbes es puramente inocente, pues carece de perversidad moral $^{32}$. El mismo Schmitt lo sabe, pues afirma que los filósofos políticos del XVIII pensaban que en el estado de naturaleza los hombres son malos "igual que los animales que lo hacen movidos por sus instintos (hambre, rapacidad, miedo, celos)” (SCHMITT, 1998, p. 89). Para Strauss, una crítica al liberalismo debería, desde los paradigmas de Schmitt, abandonar

30 Para la posición de Strauss respecto al Estado moderno y la polis antigua, ver la carta que le dirige a Karl Löwith el 20 de agosto de 1946 (STRAUSS; LÖWITH, 1983, p. 113).

31 "En consecuencia queda en pie un hecho sin duda notable y que no dejará de inquietar a muchos: que todas las teorías políticas propiamente dichas presuponen que el hombre es 'malo', y lo consideran como un ser no sólo problemático sino 'peligroso' y 'dinámico'" (SCHMITT, 1998, p. 91). Páginas antes: "Io importante es si el hombre se toma como presupuesto problemático o no problemático de cualquier elucubración política ulterior, esto es, si el hombre se entiende como un ser 'peligroso' o inocuo, si constituye un riesgo o una amenaza, o si es enteramente inofensivo" (SCHMITT, 1998, p. 88).

32 "En esta guerra de todos contra todos, se da una consecuencia: que nada puede ser injusto. Las nociones de derecho e ilegalidad, justicia e injusticia están fuera de lugar" (Leviatán, XIII, p. 104). 
la tesis de la maldad inocente, y sustituirla por una auténtica maldad moral. El motivo es simple: la oposición entre maldad y bondad "pierde su nitidez", e incluso "su sentido" si se entiende la maldad de modo inocente (MEIER, 2008, p. 157). Esto implica que la maldad inocente puede prescindir de la política, al menos como la concibe Schmitt. La política no es intrínsecamente necesaria en ese contexto, pues una maldad inocente puede ser neutralizada. Sin embargo, la política que afirma Schmitt exige una maldad más marcada, que haga realmente inevitable el conflicto, y que de espacio para una afirmación schmittiana de lo político. El problema es que esa maldad no puede ser celebrada, sino sólo reconocida (¿cómo celebrar la perversidad moral?). Desde luego, Schmitt es perfectamente consciente del carácter problemático del hombre (de allí sus alusiones a Plessner), pero - a ojos de Strauss - no explicita suficientemente su propia antropología.

Strauss cree, en particular, que la relación de Schmitt para con la moral es al menos equívoca. Lo moral, según Schmitt, es privado; pero en último término El concepto de lo político quiere rescatar la política en cuanto resguarda la seriedad de la vida humana. Sólo la política nos confronta a cuestiones realmente radicales, sólo la política nos confronta a posibilidades existenciales últimas. Pero ese es un problema moral, o al menos es también un problema moral: ¿cuál debe ser la actitud del hombre frente a las alternativas radicales? En tanto Schmitt acepta la definición liberal de lo moral (en cuanto reduce lo moral al ámbito privado), no ve que el problema político, tal como él lo define, es también moral. Esto puede explicarse de otro modo. La amenaza que se cierne sobre lo político hace inevitable el juicio moral sobre lo político: en ausencia de lo político, nuestras vidas perderían seriedad, serían vidas vanas, y ése es un problema moral. Sin embargo, la comprensión schmittiana de la esencia de lo político condena cualquier aproximación moral hacia la política: se trata de fenómenos "autónomos". Es cierto que la naturaleza de esa autonomía es muy compleja, y Schmitt parece usar el término de modo retórico. Con todo, el jurista alemán parece ocultar constantemente sus juicios morales, intentando presentarlos como si fueran puramente descriptivos. Para Strauss, una afirmación de lo político no podría hacerse desde la perspectiva de parcelas más o 
menos aisladas, pues lo político no es un fenómeno que pueda separarse de las otras realidades ni reducirse a la soberanía estatal, sino que es arquitectónico respecto del todo (ZUCKERT; ZUCKERT, 2006, p. 191192; LURI, 2012, p. 117) 33 .

Por otro lado, la aceptación, aunque fuera retórica, de la definición liberal de lo moral, conduce finalmente a Schmitt a afirmar el conflicto, sin emitir ningún tipo de juicio sobre sus motivos. Schmitt se inclina, en este texto, a la neutralidad respecto de los motivos. Le interesa afirmar la pura realidad del conflicto, sin percatarse de que su neutralidad lo acerca al liberalismo: es tan tolerante, dice Strauss, como los liberales, aunque con una intención opuesta (MEIER, 2008, p. 165; ver SFEZ, 2003, p. 176-181) ${ }^{34}$. Schmitt pone el acento en la importancia de definir al enemigo, de saber quién es el enemigo, pero nunca se detiene en la legitimidad de los motivos para considerar a tal o cual como enemigo. Esta consideración sugiere que El concepto de lo político es un texto decisionista - en plena continuidad con Teología política-, pues el énfasis sigue puesto en la decisión que debe tomar el soberano: su tarea más importante es la de designar al enemigo, y esa decisión ordena (¿y da sentido?) a todo el resto de la vida política (LÖWITH, 2006, p. 53, ver también p. 57). Según Karl Löwith, hay en Schmitt algo así como una "indiferencia radical frente a todo contenido político", que lo vuelve puramente formal. En consecuencia, todos los contenidos tienen el mismo valor (LÖWITH, 2006, p. 64).

Strauss concluye que Schmitt sólo prepara la crítica radical al liberalismo, pero no la formula acabadamente. No podría ser de otro modo, pues el carácter de su discurso es polémico, antagónico. Y, por lo mismo, queda atrapado en el horizonte del liberalismo. Strauss le reprocha a Schmitt que su crítica al liberalismo no quiera ser algo más que

33 Hugo Herrera intenta aproximar los pensamientos de Schmitt y Aristóteles, afirmando que en ambas filosofías lo político tiene un carácter total. La diferencia es que en Aristóteles esa totalidad tiene un carácter arquitectónico: la política no tiene vocación a substituirse al todo, sino ordenar el todo (sobre esto, ver DESCOMBES, 2008, p. 41). En Schmitt, la totalidad está comprendida desde la enemistad cuya intensidad puede ser tal que lo transforma todo en político: es la hostilidad exterior la que revela la verdad sobre sí a la propia comunidad. No hay nada semejante en Aristóteles (HERRERA, 2014, p. 112-117).

34 Aron ve el mismo problema: la distinción amigo-enemigo carece de normatividad intrínseca, y excluye cualquier arbitraje de la razón (DE LIGI0, 2012; RAYNAUD, 2014; LÖWITH, 2006, p. 53). 
antagónica. Porque el "saber íntegro" al que Schmitt alude al final de su texto (1998, p. 127) no es nunca polémico, sino de modo casual. Un "saber íntegro de las cosas humanas" requiere salir del terreno de la polémica. En definitiva, el registro utilizado por Schmitt - preso de la dialéctica entre amigo y enemigo- le impide elaborar una crítica coherente del liberalismo, una crítica que no quede atrapada en las redes del propio liberalismo. En el fondo, el reproche de Strauss a Schmitt parece ser el siguiente: la aproximación polémica a las cosas humanas (y, por tanto, la aproximación polémica al liberalismo) no puede aspirar a alcanzar ningún tipo de verdad (salvo de modo casual) (MEIER, 2008, p. 167) ${ }^{35}$. Por un lado, es necesariamente tributaria de la posición criticada; $\mathrm{y}$, por otro, es incapaz de moderación (con el enemigo no hay que ser moderado) ${ }^{36}$. Esto puede explicar que Schmitt insista tanto en la fenomenología del enemigo, y se detenga tan poco en la del amigo ${ }^{37}$. Schmitt, en definitiva, no está haciendo filosofía, sino política, al afirmar que "todos los conceptos, ideas y palabras poseen un sentido polémico", y "se formulan con vistas a un antagonismo concreto" (SCHMITT, 1998, p. 63) $)^{38}$. En rigor,

35 Si aplicamos la tesis de Schmitt sobre el carácter antagónico de los conceptos políticos a su propia doctrina, quizás podamos comprender mejor sus bruscas oscilaciones teóricas (y prácticas). Ésa es, al menos, la tesis de Karl Löwith (2006, passim).

36 Hugo Herrera critica, desde Aristóteles, esta tesis straussiana: dado que el ser humano "jamás se halla en situaciones neutrales", toda teoría política que quiera abarcar lo concreto "puede y debe ser práctica o polémica" (HERRERA, 2014, p. 121). El problema es precisamente si podemos asumir que lo "práctico" es equivalente a lo polémico. Es evidente que la crítica straussiana no supone que los conceptos están enunciados por ángeles en contextos neutrales. El problema es que, en Schmitt, "lo práctico" está marcado por la distinción entre amigo y enemigo, y es a la luz de esa afirmación central que debe leerse la tesis de que todos los conceptos políticos son antagónicos. Por ese motivo, Schmitt puede decir que los conceptos políticos están referidos "a un antagonismo concreto", "a una situación concreta cuya consecuencia última es una agrupación según amigos y enemigos" (SCHMITT, 1998, p. 63): la praxis aristotélica tiene poco que ver con esto. Incluso suponiendo que todo argumento práctico sea polémico, eso no nos obliga a quedarnos en ese registro; $y$ Schmitt nunca intenta salir ni tomar distancia de él. Más bien, parece complacerse.

37 En esta dirección va también una crítica de Aron a Schmitt: el enemigo es imprescindible para la especificación de lo político, pero no lo agota (DE LIGI0, 2012; TUCHSCHERER, 2003, p. 33; CRUZ PRADOS, 1999, p. 298).

38 Esto puede explicar la notable diferencia de tono entre Schmitt y Strauss: allí donde el primero es fuerza y retórica, el segundo es reserva y moderación. Hay un texto de Strauss — que intenta explicar cómo leer a Jenofonte — que podemos aplicar a su propia diferencia con Schmitt: "Una segunda educación nos es necesaria para acostumbrarnos a la noble reserva y a la grandeza calma de los clásicos. Jenofonte se limitaba a cultivar exclusivamente este aspecto de los escritos clásicos que es completamente extraño al gusto moderno. No es sorprendente entonces que sea, en nuestros días, despreciado 0 ignorado [... L Los lectores modernos que tienen la suerte de tener una preferencia natural por Jane Austen más que por Dostoievski comprenden a Jenofonte más fácilmente que los otros" (Strauss, 2013, p. 185). Strauss cree, en definitiva, que

Rev. Filos., Aurora, Curitiba, v. 30, n. 50, p. 397-423, maio/ago. 2018 
puede decirse que, para Strauss, el filósofo político debe ocuparse de los problemas permanentes, más que de la crítica polémica a tal o cual posición dominante (STRAUSS, 1978, p. 14) $)^{39}$.

\section{Leo Strauss y Carl Schmitt}

El proyecto intelectual desplegado por Strauss puede leerse, si se quiere, desde este desacuerdo: una crítica antagónica al liberalismo moderno es necesariamente insuficiente. Una crítica radical al liberalismo exige una comprensión plena $-\mathrm{y}$ benevolente - de las categorías liberales, tarea que Schmitt no emprendió. Parafraseando al mismo Schmitt, podríamos decir que, si es cierto que no hay una política liberal sui generis, tampoco hay una crítica antagónica del liberalismo que pueda llegar hasta el final, ni alcanzar un "saber íntegro": la negación del liberalismo no es una alternativa al liberalismo (ZUCKERT; ZUCKERT, 2006, p. 187). Esa es, nos parece, la lección que Strauss aprendió de Schmitt, y que aclara por qué el comentario al Concepto de lo político es la primera manifestación de su madurez intelectual. En efecto, a partir de ese momento Strauss empieza a considerar seriamente el estudio de los fundamentos del paradigma moderno, y su polémica con los paradigmas clásicos, para examinar con la mayor honestidad posible ambas posiciones. Por lo mismo, el estudio de Hobbes ocupa un lugar central en la trayectoria de Strauss: si acaso queremos comprender el mundo moderno, es indispensable una consideración detenida (y no meramente polémica) de la filosofía contenida en el Leviatán.

En 1941, Strauss dictó una conferencia en Nueva York sobre el nihilismo alemán. Allí, explica el ambiente que reinaba en la juventud alemana después de la gran guerra. Retomando casi palabra por palabra algunos pasajes de Schmitt, Strauss explica por qué el nihilismo tentó a la juventud alemana en los años 20 y 30. Según Strauss,

"la indignación es mala consejera"y, por lo mismo, hay algún peligro si perseguimos el objetivo de Sócrates"con los medios y el humor de Trasímaco" $(1953$, p. 6).

39 La lectura esotérica que propone Strauss de los textos clásicos está basada en la existencia de problemas permanentes. Esta premisa es criticada por la tradición contextualista (BOUCHER, 1984 y MAJOR, 2005). 
el nihilismo que conquistaba a la juventud alemana sabía muy bien aquello que rechazaba (el pacifismo, el internacionalismo y la primacía del comercio), pero no tenía claro con qué reemplazarlo. Estos jóvenes, dice Strauss, necesitaban maestros que les hubieran explicado en un lenguaje claro la significación positiva de sus aspiraciones. En lugar de eso, encontraron maestros que, de modo más o menos consciente, los dirigieron hacia el nihilismo. Strauss da algunos ejemplos de esos maestros: Carl Schmitt, Ernst Junger y Martin Heidegger, entre otros (STRAUSS, 1999, p. 362) ${ }^{40}$. La acusación es particularmente severa: estos intelectuales, que ejercían un magisterio decisivo entre los más jóvenes, son responsables de haberlos conducido hacia el nihilismo, que Strauss caracteriza como una voluntad destructiva sin proyecto claramente definido. Cuando nuestros principios, dice Strauss en otro texto, no tienen otro fundamento que nuestras preferencias ciegas, entonces ya no hay interdicciones legítimas: el nihilismo se identifica así con el abandono del derecho natural (STRAUSS, 1953, p. 16). Y, prosigue, la consecuencia inevitable del nihilismo es el oscurantismo fanático (STRAUSS, 1953, p. 18) ${ }^{41}$. Para Strauss, estos son problemas de primer orden, y que de hecho iluminan buena parte de su obra: ¿cuáles son los fundamentos intelectuales que permitieron las barbaries perpetradas durante el siglo XX? Así, la política schmittiana le permite a Strauss comprender ciertos problemas: hay allí un germen nihilista que puede tener consecuencias muy graves. Desde luego, afirmar la gravedad de sus consecuencias no implica que sus premisas sean falsas, y es precisamente por ese motivo que se requiere un examen filosófico más que una respuesta antagónica. Tomarse en serio el problema de la modernidad exige intentar dar respuestas a este tipo de preguntas, y para Strauss ese desafío empieza por una nueva consideración de las teorías

40 La crítica final de Strauss a Schmitt debe ser vista a la luz de su crítica, análoga en muchos sentidos, a Martin Heidegger (STRAUSS, 1989).

41 En una carta inédita de 1965, dirigida a Hasso Hoffman, Strauss afirma que el elemento decisivo de la doctrina de Schmitt es su patriotismo alemán: sólo desde allí es posible comprender su noción de lo político. Sin embargo, no hay nunca en Schmitt una explicitación de qué significa ser patriota, ni de cuáles son las exigencias y limitaciones del patriotismo (carta de Strauss a Hoffmann del 27 de enero de 1965, Strauss Archive, Regenstein Library, University of Chicago. Agradezco a Robert Howse el haberme facilitado el acceso a este texto).

Rev. Filos., Aurora, Curitiba, v. 30, n. 50, p. 397-423, maio/ago. 2018 
clásicas del derecho natural ${ }^{42}$, pero no tiene por qué desembocar a priori en una propuesta antiliberal: la crítica de Strauss al liberalismo es más radical que la de Schmitt en cuanto intenta no depender de él; y es menos radical en cuanto también es capaz de considerar los méritos de la democracia liberal (ZUCKERT; ZUCKERT, 2006, p. 187-190).

Pero ¿cómo comprender el error de Schmitt? ¿Cómo dar cuenta de sus dificultades para comprender el fenómeno político y, en definitiva, el fenómeno humano? En una carta a Voegelin, Strauss dice que la "raíz de las tinieblas de la modernidad" reside en el "oscurecimiento de la diferencia entre teoría y praxis", un oscurecimiento que conduce en un primer tiempo a una "reducción de la praxis a la teoría"; y luego, por reacción, al rechazo de la teoría en nombre de una praxis que deja de ser inteligible en tanto praxis (STRAUSS; VOEGELIN, 1993, p. 65-66). Estas líneas pueden aplicarse a Carl Schmitt, cuya concepción de lo político busca ser tan autónoma de cualquier consideración externa, que pierde toda posibilidad de fundamentación racional: la praxis schmittiana queda suspendida sobre sí misma, suspendida sobre una decisión que es, por definición, ininteligible. Si la filosofía de la historia busca subsumir toda praxis en una teoría que la comprende y la explica absolutamente, la política schmittiana busca liberar a la praxis de cualquier intromisión externa (AUBENQUE, 2001, p. 239). Pero es precisamente ese equívoco el que conduce al nihilismo, y a aquello que Strauss llama las tinieblas modernas: quedamos completamente desprovistos de criterios orientadores, pues somos incapaces de ver que la teoría debe iluminar la praxis sin absorberla, pues ésta tiene su autonomía en virtud de la contingencia de las cosas humanas: El Concepto de lo político ignora la prudencia, ese "dios del mundo inferior" (STRAUSS, 1953, p. 321). En la medida en que Schmitt no comprende adecuadamente esa relación, puede decirse que su filosofía no supera las aporías propias de la modernidad.

42 Robert Howse (2014, p. 25-50) defiende, con muy buenas razones, la tesis según la cual Natural Right and History es, de algún modo, una respuesta a Schmitt. Brett Dutton (2002) piensa, más bien, que Strauss le responde a Schmitt con su libro The City and the Man. 


\section{Referencias}

AUBENQUE, P. Problèmes aristotéliciens. Philosophie pratique. Paris: Vrin, 2001. BALIBAR, É. Introducción. In: SCHMITT, C. Le Léviathan dans la doctrine de l'État de Thomas Hobbes: sens et échec d'un symbole politique. Paris: Seuil, 2002. BOUCHER, D. The Denial of Perennial Problems: The Negative Side of Quentin Skinner's Theory. Interpretation, v. 12, p. 287-300, 1984.

CONSTANT, B. De la liberté des anciens comparée à celle des Modernes. In: CONSTANT, B. Écrits politiques. Paris: Gallimard, 1997.

CRUZ PRADOS, A. Ethos y Polis. Bases para una reconstrucción de la filosofía política. Pamplona: EUNSA, 1999.

DE LIGIO, G. La vertu politique. Aron penseur de l'ami et de l'ennemi. Etudes internationales, v. 43, n. 3, p. 405-420, 2012.

DESCOMBES, V. Philosophie du jugement politique. Paris: Seuil, 2008.

DESMONS, E. Mourir pour la patrie ?. Paris: PUF, 2001.

DUTTON, B. Leo Strauss's Recovery of the Political: The City and the Man as a reply to Carl Schmitt's The Concept of the Political. Sydney: University of Sydney, 2002 GALLI, C. Schmitt y Maquiavelo. In: GALLI, C. (ed.). La mirada de Jano: ensayos sobre Carl Schmitt. México, D. F.: Fondo de Cultura Económica, 2010.

HERRERA, H. E. Aristotelismo político schmittiano. Revista Pléyade, v. 13, p. 107-123, 2014.

HERRERO, M. El nomos y lo político: la filosofía política de Carl Schmitt. Pamplona: Eunsa, 1997.

HILB, C. Leo Strauss: el filósofo en la ciudad. Buenos Aires: Prometeo, 2011.

HIRSCHMAN, A. O. Les passions et les intérêts: justifications politiques du capitalisme avant son apogée. Paris: Presses Universitaires de France, 1997.

HOBBES, T. Leviatán, o la materia, forma y poder de una república eclesiástica y civil. México D. F.: Fondo de Cultura Económica, 1994. 
HOBBES, T. De Cive. Madrid: Alianza, 2000.

HOBBES, T. Elementos de Derecho Natural y Político. Madrid: Alianza, 2005.

HOWSE, R. From Legitimacy to Dictatorship - and Back Again. Leo Strauss's Critique of the Anti-Liberalism of Carl Schmitt. Canadian Journal of Law and Jurisprudence, v. 10, n. 1, p. 77-103, 1997.

HOWSE, R. Leo Strauss, Man of Peace. Cambridge: Cambridge University Press, 2014.

HÜNING, D. Hobbes on the Right to Punish. In: SPRINGBORG, P. (ed.). The Cambridge Companion to Hobbes's Leviathan. Cambridge: Cambridge University Press, 2005. p. 217-240.

KANT, I. Sobre la paz perpetua. Madrid: Tecnos, 1998.

LÖWITH, K. El decisionismo ocasional de Carl Schmitt. In: LÖWITH, K. Heidegger, pensador de un tiempo indigente: sobre la posición de la filosofía en el siglo XX. Buenos Aires: Fondo de Cultura Económica, 2006. p. 43-89.

LURI, G. Erotismo y prudencia: biografía intelectual de Leo Strauss. Encuentro, 2012.

MAJOR, R. The Cambridge School and Leo Strauss: Texts and Context of American Political Science. Political Research Quarterly, v. 58, p. 477-485, 2005.

MANENT, P. Notre destin liberal. In: MEIER, H. Carl Schmitt, Leo Strauss et la Notion de politique: un dialogue entre absents. Paris: Julliard, 1990.

MANENT, P. La leçon de Carl Schmitt. Commentaire, n. 146, 2014.

MAQUIAVELO, N. Discursos sobre la primera Década de Tito Livio. Madrid: Alianza, 2000.

MAQUIAVELO, N. El Príncipe. Madrid: Alianza, 2010.

MEIER, H. Carl Schmitt, Leo Strauss y El concepto de lo político: sobre un diálogo entre ausentes. Buenos Aires: Katz, 2008.

MEIER, H. Die Lehre Carl Schmitts: Vier Kapitel zur Unterscheidung Politischer Theologie und Politischer Philosophie. Berlin: Metzler'sche, 2013.

MÉNISSIER, T. Machiavel ou la politique du centaure. Paris: Hermann, 2010. 
MULLER, J.-W. Re-imagining Leviathan: Schmitt and Oakeshott on Hobbes and the Problem of Political Order. In: TRALAU, J. (ed.). Thomas Hobbes and Carl Schmitt. The Politics of Order and Myth. London: Routledge, 2011.

OAKESHOTT, M. L'association civile selon Hobbes: suivie de cinq essais sur Hobbes. Paris: Vrin, 2011.

RAYNAUD, P. Raymond Aron lecteur de Carl Schmitt. Du bon usage des maladies. In: SUR, S. (ed.). Carl Schmitt: concepts et usages. Paris: CNRS Éditions, 2014. p. 215-230.

SARAVIA, G. Thomas Hobbes y la filosofía politica contemporánea: Carl Schmitt, Leo Strauss y Norberto Bobbio. Madrid: Dykinson, 2011.

SCHMITT, C. The Leviathan in the State Theory of Thomas Hobbes. Meaning and Failure of a Political Symbol. Chicago: University of Chicago Press, 1992.

SCHMITT, C. El concepto de lo político. Madrid: Alianza Editorial, 1998.

SCHMITT, C. La dictadura. Madrid: Alianza Editorial, 1999.

SFEZ, G. Leo Strauss lecteur de Machiavel: la modernité du mal. Paris: Ellipses, 2003.

SMITH, S. B. (ed.). The Cambridge Companion to Leo Strauss. New York; Cambridge: Cambridge University Press, 2009.

STRAUSS, L. Natural Right and History. Chicago: University of Chicago Press, 1953.

STRAUSS, L. Carta de Strauss a Hoffmann del 27 de enero de 1965. Strauss Archive, Regenstein Library. Chicago: University of Chicago, 1965.

STRAUSS, L. Thoughts on Machiavelli. Chicago: University of Chicago Press, 1978.

STRAUSS, L. An Introduction to Heideggerian Existentialism. In: STRAUSS, L. The Rebirth of Classical Political Rationalism. Chicago: University of Chicago Press, 1989. p. 27-46.

STRAUSS, L. Spinoza's Critique of Religion. Chicago: University of Chicago Press, 1997.

STRAUSS, L. German Nihilism. Interpretation, v. 26, n. 3, p. 352-378, 1999. 
STRAUSS, L. La filosofía política de Hobbes: su fundamento y su génesis. Buenos Aires: Fondo de Cultura Económica, 2006.

STRAUSS, L. Qu'est-ce que la philosophie politique? Paris: PUF, 2010.

STRAUSS, L. On Tyranny. Chicago: University of Chicago Press, 2013.

STRAUSS, L.; LÖWITH, K. Correspondence Concerning Modernity. Independent Journal of Philosophy, v. 4, p. 105-119, 1983.

STRAUSS, L.; SCHOLEM, G. Correspondencia 1933-1973: Leo Strauss y Gershom Scholem. Valencia: Pre-textos, 2010.

STRAUSS, L.; VOEGELIN, E. Faith and Political Philosophy: The Correspondence Between Leo Strauss and Eric Voegelin, 1934-1964. University Park: Pennsylvania State University Press, 1993.

TUCHSCHERER, E. Le décisionnisme de Carl Schmitt: théorie et rhétorique de la guerre. Mots: les langages du politique, v. 73, p. 25-41, 2003.

ZARKA, Y.-C. Le mythe contre la raison: Carl Schmitt ou la triple trahison de Hobbes. In: ZARKA, Y.-C. (ed.). Carl Schmitt ou le mythe du politique. Paris: PUF, 2009. p. 47-70.

ZUCKERT, C.; ZUCKERT, M. The Truth about Leo Strauss: Political Philosophy and American Democracy. Chicago: University of Chicago Press, 2006.

Recibido: 22/11/2017

Received: 11/22/2017

Recebido: 22/11/2017

Aprobado: 27/02/2018

Approved: 02/27/2018

Aprovado: 27/02/2018 